other way's. Although there is no doubt about the hereditary nature careful investigation shows that the previous predisposition is likely to be increased by unsatisfactory environment, particularly during the period prior to conception and during the early period of embryonic life. There is, therefore, good reason to hope that the antenatal clinics, whose work is so valuable in other ways, will help considerably to diminish the incidence of this blight. The infant welfare centres help too. Their greatest value, however, will be shown when they recognize mental defectives at an early stage and give satisfactory directions for regulating their lives. When the school clinics are able to tackle psychological problems as well as physical ones, they will constitute another important factor in dealing with the problem, as they will recognize almost all the cases overlooked at an earlier stage and indicate what must be done to protect the community.

\section{THE NATURE OF MENTAL DEFICIENCY.}

\author{
By A. F. TREDGOLD, \\ M.D., M.R.C.P., F.R.S.E.
}

Lecturer on Mental Deficiency at London University; Associate Physician in Psychological Medicine, University College Hospital, Ec.

\section{(A Fellowship of Medicine Post-Graduate Lecture.)}

SINCE the beginning of this century the interest of the general public and the medical profession in the subject of mental deficiency has been steadily increasing. The reason is clear. It is now known that the number of mental defectives in the community is very considerable, greater, in fact, than that of the insane. It probably amounts to at least 8 per 1,000 of the total population of the country. It is also realized that defectives are a serious economic burden and, in many cases, a no less serious social menace ; consequently, that their ascertainment, correct diagnosis, and proper administrative care have become matters which the nation can no longer afford to neglect. At the present day the subject is undoubtedly one concerning which every medical practitioner must have an adequate working knowledge. This knowledge must be based upon an accurate concept of the nature of mental deficiency, and it is with this fundamental point that I propose to deal in this lecture.

The term mental deficiency is comparatively new. Literally, it may be said to embrace all conditions of mind in which there is marked diminution of capacity. It may, for instance, be applied to the dement and the insane. For some years past, however, the term has gradually been acquiring a more restricted and specific meaning, and at the present day, when we speak of mentab deficiency we mean a condition of incoms plete mental development, or, as it is techfo nically termed, " amentia."

From at least as early as the fourteenth, to near the close of the nineteenth century, the only forms of such incomplete mental development which were generally recognized were the severe and obvious ones termed idiocy and imbecility. Towards the end of the last century, however, it was clearly demonstrated that less pronounced grades of defect existed, and these occurred amongst school children as well as amongst the adult $₹$ population. In the elementary schools, at 음 which attendance had then become compul- $\frac{7}{0}$ sory, it was found that there was a class of children who, whilst not so defective in $\tilde{\sigma}$ understanding as the imbeciles, nevertheless $N$ suffered from a degree of mental defect which $\underset{\omega}{N}$ seriously interfered with their education. Amongst the general population it was found $\stackrel{C}{C}$ that a class existed who, whilst similarly $\stackrel{\mathbb{Q}}{\rightarrow}$ not so defective as imbeciles, nevertheless 0 suffered from such a degree of defect that they were unable to compete on equal terms $\stackrel{\circ}{\overparen{D}}$ with their normal fellows, or to maintain an 
independent existence without some external care, supervision or control.

In the course of time the recognition of these two groups resulted in the passing of two Acts of Parliament. The first of these was the Defective and Epileptic Children (Education) Act, I899, which was subsequently replaced by the consolidated Education Act, I92 r. The second was the Mental Deficiency Act, I9 3, which was subsequently amended in certain particulars by the Mental Deficiency Act, I927. The Education Act, I92 I, and the Mental Deficiency Acts, 1913 and 1927 , are therefore the authoritative and legal pronouncements as to what constitutes mental deficiency.

Unfortunately, the detinitions in these respective Acts are not quite in agreement, and this has led to some confusion, and to two different types of individuals being designated mental defectives. This discrepancy in the definitions is in large measure attributable to the cifferent purposes underlying the Education and Mental Deficiency Acts. The purpose of the Education Act is to provide suitable education for those who cannot profitably be taught in ordinary schools, hence the criterion laid down is that of educational incapacity. The main purpose of the Mental Deficiency Acts, on the other hand, is to provide suitable care and control, and hence the criterion laid down is that of social incapacity. In consequence of these differences, it is necessary to describe these two types of mental defectives separately.

The Education Act, r92 I, Part V, defines mentally defective children as those children who, "not being imbecile, and not being merely dull and backward, are defective : that is to say, by reason of mental defect are incapable of receiving proper benefit from the instruction in the ordinary public elementary schools.

Although the only test laid down by this definition is that of scholastic ineducability, I am of the opinion that the intention of the framers of the Act was not to legislate for children who were solely and simply defective in capacity for school learning, but for children who, whilst suffering from a defect of this kind, were also defective in general intelligence. That is to say, for children who, subsequently to leaving school, would be found to suffer from social incapacity identical with that which constitutes mental deficiency under the M.D. Acts. In many, perhaps even in the majority, of children who are certified as defective under the Education Act, this is actually the case, for the reason that defective scholastic educability and defective social capacity are often associated. But this association is by no means invariable. A large number of children have a very low capacity for school learning, but are by no means lacking in general intelligence, and there is no doubt that many such children are certified as mentally defective under the Education Act, and sent to special schools, yet who subsequently prove quite capable of fending for themselves. In my opinion, it is unfair to stigmatize such children as mentally deficient. I regard them as belonging to the lower stratum, the "dull and backward" group, of the normal population. They are certainly in need of some form of special teaching, but it should be possible to provide this without branding them as mental defectives. Whatever may have been the intention of the Act, however, there is no doubt that as the definition stands it can be interpreted as applying to children suffering merely from scholastic ineducability, and that children of this kind form one variety of mental defectives recognized by the Law. The Education Act, however, only applies to children under the age of 16 years, and the majority of children certified under this Act do subsequently evince social incapacity and prove to be certifiable under the M.D. Acts. Usually, therefore, when the term mental defective is used, it is used in the meaning of the definitions contained in the Mental Deficiency Acts. it is with mental deficiency as there defined that I now propose to deal. 
The 1913 Mental Deficiency Act did not define mental deficiency as such, but it defined four classes of defectives, namely: idiots, imbeciles, feeble-minded, and moral imbeciles. With the purpose of making it clear that the Act only referred to conditions of incomplete mental development, and not to states of mental disorder or decay, it specified that the defect must have been present "from birth or from an early age." Experience of the working of the Act showed that these words caused considerable administrative difficulties, and it was largely to remedy them that the amending Act was passed in 1927. In this Act, in addition to certain alterations in the definitions of the four classes, a new section was added defining mental deficiency. This, Section I (2) is as follows:-

"Mental defectiveness means a condition of arrested or incomplete development of mind existing before the age of 18 years, whether arising from inherent causes or induced by disease or injury."

It is at once apparent that this definition is based upon a much wider concept of the nature of mental deficiency than that which was held by the Law before 19r3. Prior to that date mental defect was legally and commonly regarded as consisting of a pronounced want of understanding. The present definition says nothing about understanding or any particular mental attribute. It simply says "arrested or incomplete development of mind." It therefore becomes of importance to consider what form and degree of arrest or incompletion are necessary to bring the individual within the various classes of defectives defined by the Act.

In order' rightly to understand this fundamental question, it is necessary to make a short digression, and to refer very briefly to certain points regarding the constitution of mind. We may regard mind as divisible into three main groups of functions, namely: (I) instinctive, (2) emotional, and (3) intellectual. The instinctive functions, or instincts, of man consist of certain in- $\frac{\vec{D}}{\mathrm{D}}$ herited tendencies to particular modes of $\frac{2}{C}$ purposive behaviour. These modes of behaviour have in all probability been $\stackrel{\text { S }}{\stackrel{9}{9}}$ gradually acquired by man's primitive human and pre-human ancestors in the $\frac{\bar{\sigma}}{\bar{\sigma}}$. course of their past evolution. They were $\underset{\varnothing}{\circ}$ vital to the survival of the individual and $\%$ the perpetuation of his kind, and hence they $\vec{O}$ became organically fixed ; that is to say, they impressed a pattern upon the central nervous $\vec{\omega}$ system, and this pattern has been hereditarily $\frac{\circ}{\circ}$ transmitted. At the present day human 3 . instincts consist of a deeply-ingrained $\dot{\omega}$ series of powerful urges to particular modes $\stackrel{\omega}{.}$ of conduct, such, for example, as those of $\vec{\infty}$ sex, self-preservation, combat, acquisition, $\stackrel{\infty}{\circ}$ self-display, and many others. They may be regarded as the basis of most forms of $\frac{D}{O}$ human conduct.

The emotional functions are the affective $\overrightarrow{0}$ or feeling processes of mind. They ha probably been evolved in consequence of. changes induced in the central nervous system by the operation of the various instincts, and each instinct is accompanied $\frac{}{\square}$ by its corresponding emotion. The instinct $\underset{\vec{P}}{\vec{P}}$ of combat, for instance, is accompanied by $\frac{3}{3}$ the emotions of anger and rage ; that of selfdisplay by the emotion of elation. Emotions, however, are not restricted to the $\frac{\overline{0}}{3}$. manifestation of instincts; they are associated with ideas of behaviour, and they then constitute the sentiments or senses. The emotion which attaches to percepts or concepts of harmony in form, colour, or $?$ sound, for instance, constitutes the æsthetic $\frac{?}{2}$. sentiment; that which attaches to ideas of right and wrong, and of moral duty, constitutes the moral sentiment. The im- ్N portance of the emotions is that they ${ }_{\sigma}^{\omega}$ serve to reinforce and increase the driving force of the instinct or idea. They are thus exceedingly powerful incentives to $\stackrel{?}{?}$ behaviour.

The intellectual functions consist of the $\frac{\overrightarrow{0}}{\mathrm{D}}$ perceiving, understanding, deliberating, $\frac{\mathrm{P}}{\mathrm{O}}$ discriminating, planning, co-ordinating and 
controlling processes of mind. Although the rudiments of these are present in many of the lower animals, it is not until the stage of man is reached that they play any considerable part in mental activity. Further, their development increases with man's gradual evolution from a state of savagery to one of civilization. The intellectual functions, together with the higher sentiments, may be regarded as the summation of the mental architecture, and their importance consists in the increased capacity they bestow upon man for acquiring knowledge, for understanding relationships, making plans, learning from experience, and modifying and controlling primitive instincts and emotions so as to enable him to adapt himself to his surroundings, and to achieve an ideal.

In a person of superior intellectual ability all these intellectual processes are developed to a high degree. There is reason to think, however, that certain groupings of these processes may occur, and that there may be considerable differences in the development of these various groups in different individuals. The chief groups are three: (I) Those processes concerned in the acquirement of knowledge and the operations of thought. An individual with a high development of this group will be a profound scholar, but he may be devoid of any practical ability and even lacking in the capacity for adaptation to the ordinary requirements of life. (2) Those processes concerned in some specific motor or mental operation, such, for instance, as music, mechanics, art, or arithmetical calculation. An individual with a high development of this group may not be learned, and may be lacking in general intelligence, but he may be a genius in his own particular sphere. (3) Those processes concerned in the co-ordination and general control of conduct, and its adaptation to present and future needs. An individual with a high development of this group of processes may have little learning and no special ability, but he will be adaptive and the possessor of "common sense."

The intellectual functions, therefore, consist of three groups of mental processes, but the development of each group may vary considerably in different individuals. There are certain basic processes, such as attention, perception, memory and ideation, which are common to all the groups; but in addition to these there are certain functions of a more specialized kind which would appear to be peculiar to, and characteristic of, each separate group. These groups may therefore be regarded as psychological entities, inasmuch as they constitute the mental machinery (if we may use such a term) for a particular kind of performance ; in one group, that of learning ; in another, that of some highly specialized form of work; and in a third, that of adaptation to present and future requirements. With a high intellectual development a person will be learned, adaptive, and possessed of all-round practical ability, but either of these groups of processes may be present without the others. In particular, a person may be learned but unadaptive; and another person may be adaptive, but have little capacity for learning.

Let us now consider the importance respectively of the instinctive, emotional and intellectual functions of mind in enabling the individual to maintain an independent existence in a civilized community. There is no doubt that in the various forms of life below that of man, adaptation to environment, individual survival, and perpetuation of the species, are secured in a very efficient manner mainly by instincts. It is far otherwise, however, with man. Even in the case of the most primitive human types living in communities of the most simple nature, some conscious understanding of the relationship between causes and effects, some capacity to make comparisons, to form simple judgments, to learn from experience, to look ahead and make plans, and to co-ordinate behaviour 
in accordance with the plans made, are necessary if the individual is to secure food, to keep alive and to propagate his kind. Moreover, the maintenance of individual life and the safety, indeed the very existence, of such a community must often necessitate an inhibition or modification of man's primitive instincts. It would clearly be impossible for any community, however simple, to continue to exist if free and unfettered instinctive action were the order of the day; that is, if any and every individual were allowed to do what, where and when he pleased. Hence, whilst instincts and emotions would still continue to act as powerful incentives to conduct, the intellectual processes of mind gradually became of more and more importance. They were necessary to modify and guide these instincts along lines which did not conflict with the common weal. They were necessary to enable man to understand his surroundings, to make plans for contingencies, and generally to adapt himself in a satisfactory and efficient manner to the exigencies of his environment. We may say, therefore, that while in the case of the lower animals survival is largely, although perhaps not entirely, dependent upon instincts, in man it is dependent upon the intellectual functions of mind.

It has been pointed out, however, that the intellectual functions consist of three groups of processes, the development of which varies considerably in different individuals. It seems clear that these groups are not of equal value in enabling the individual to maintain an independent existence. Thus, there are many examples of persons who possess a high capacity for learning, or a degree of special ability which almost amounts to genius, and yet they are quite incapable of managing themselves or their affairs without external supervision. There are others whose-capacity for learning is decidedly subnormal, often to an extent which causes them to be certified as mental defectives and sent to special schools; and yet they are quite capable of performing remunerative work and of fending for them-क्ष selves, because they possess adaptiveness or $c$ common sense. In fact, whilst learning and $\vec{F}$ special aptitudes are undoubtedly advan $\frac{\text { ? }}{0}$ tageous to the individual, they are not essen-듬 tial to enable him to survive. Independent $\frac{\bar{c}}{\frac{5}{\sigma}}$ survival, whether in a savage or a civilized $\propto$ community, demands the presence of that group of mental processes which determine $\overrightarrow{0}$ adaptation, and if the individual is lacking $\vec{\omega}$ in this, he will be in need of some form of external care or supervision-in short, $\overrightarrow{0}$ he will be a mental defective within the 3 . meaning of the Act.

We may say, then, that the essential $\stackrel{\omega}{.}$ psychological basis of mental defect is a $\vec{\infty}$ deficiency in that group of the intellectualo functions of mind which determine adapta- $\rightarrow$ tion. It is necessary to point out, how-o ever, that although it is convenient to regard $\vec{\oplus}$ adaptation as a psychological entity, it is inల reality the sum of many mental processeg. These processes include attention, p ception, memory, ideation, deliberatio $\overline{\frac{J}{0}}$ discrimination, comparison, reasoning, provision, planning, insight, co-ordination and $\stackrel{\mathbb{Q}}{\mathscr{Q}}$ control. I do not suggest that these pro- $\overrightarrow{\overrightarrow{0}}$ cesses are independent entities like bricks which go to the making up of a house. The architecture of mind is a much more com $-\frac{-}{0}$ plicated affair than this, and is more accur - . ately conceived of as a vast and complex nexus of interdependent activities. In the same way, however, as there are variations in the development of the respective groupso which compose intellect, so there are varia tions in the development of the variouse. processes which determine adaptation Hence, defective adaptation may be of various grades, and, dependent upon the्్ defect falling more particularly upon certaino processes, it may be of various types.

(To be continued.) 